\title{
Safe Use of Opioids in Chronic Kidney Disease and Hemodialysis Patients: Tips and Tricks for Non-Pain Specialists
}

This article was published in the following Dove Press journal: Therapeutics and Clinical Risk Management

\author{
Flaminia Coluzzi id ${ }^{1,2}$ \\ Francesca Felicia Caputi ${ }^{3}$ \\ Domenico Billeci iD ${ }^{4}$ \\ Antonio Luigi Pastore ${ }^{1,5}$ \\ Sanzio Candeletti iD ${ }^{3}$ \\ Monica Rocco iD ${ }^{2,6}$ \\ Patrizia Romualdi (iD ${ }^{3}$ \\ 'Department of Medical and Surgical \\ Sciences and Biotechnologies, Sapienza \\ University of Rome, Polo Pontino, Latina, \\ Italy; ${ }^{2}$ Unit of Anesthesia, Intensive Care \\ and Pain Medicine, Sant'Andrea \\ University Hospital, Rome, Italy; \\ ${ }^{3}$ Department of Pharmacy and \\ Biotechnology, Alma Mater Studiorum \\ University, Bologna, Italy; ${ }^{4}$ Division of \\ Neurosurgery, Ca'Foncello Hospital, ASL \\ Marca Trevigiana, University of Padova, \\ Treviso, Italy; ${ }^{5}$ Unit of Urology, Sapienza \\ c/o I.C.O.T, Polo Pontino, Latina, Italy; \\ ${ }^{6}$ Department of Clinical and Surgical \\ Translational Medicine, Sapienza \\ University of Rome, Rome, Italy
}

\begin{abstract}
In patients suffering from moderate-to-severe chronic kidney disease (CKD) or end-stage renal disease (ESRD), subjected to hemodialysis (HD), pain is very common, but often underestimated. Opioids are still the mainstay of severe chronic pain management; however, their prescription in CKD and HD patients is still significantly low and pain is often under-treated. Altered pharmacokinetics and the lack of clinical trials on the use of opioids in patients with renal impairment increase physicians' concerns in this specific population. This narrative review focused on the correct and safe use of opioids in patients with CKD and HD. Morphine and codeine are not recommended, because the accumulation of their metabolites may cause neurotoxic symptoms. Oxycodone and hydromorphone can be safely used, but adequate dosage adjustments are required in CKD. In dialyzed patients, these opioids should be considered as second-line agents and patients should be carefully monitored. According to different studies, buprenorphine and fentanyl could be considered firstline opioids in the management of pain in CKD; however, fentanyl is not appropriate in patients undergoing HD. Tapentadol does not need dosage adjustment in mild-to-moderate renal impairment conditions; however, no data are available on its use in ESRD. Opioidrelated side effects may be exacerbated by common comorbidities in CKD patients. Opioidinduced constipation can be managed with peripherally-acting- $\mu$-opioid-receptor-antagonists (PAMORA). Unlike the other PAMORA, naldemedine does not require any dose adjustment in CKD and HD patients. Accurate pain diagnosis, opioid titration and tailoring are mandatory to minimize the risks and to improve the outcome of the analgesic therapy.
\end{abstract}

Keywords: opioids, chronic kidney disease, pain, hemodialysis, neuropathic pain, PAMORA

\section{Introduction}

Chronic kidney disease (CKD) is an increasing health problem worldwide. Many elements, such as genetic or epigenetic factors, ${ }^{1,2}$ age population, economic, and social disadvantage, ${ }^{3}$ seem to have a relevant impact in the development of moderateto-severe $\mathrm{CKD}$. The increase in the average age of the world population that occurred in the latest years highlighted the complexity of geriatric patients' management and the increasing number of patients suffering from CKD. ${ }^{4}$ Indeed, most of the new CKD diagnoses concern people $\geq 65$ years, in which the increased risk of renal function impairment is mainly related to the age and to the presence of comorbidities, such as diabetes mellitus, hypertension, and heart failure. ${ }^{5-8}$ Nevertheless, the incidence of CKD in children is not negligible. ${ }^{9}$ The top causes of pediatric CKD are
Correspondence: Flaminia Coluzzi Department of Medical and Surgical Sciences and Biotechnologies, Sapienza University of Rome, Corso della Repubblica 79, Polo Pontino 04100, Latina, Italy

Tel +390633775673

Email flaminia.coluzzi@uniromal.it 
generally represented by congenital abnormalities of kidneys and urinary tract, ${ }^{10,11}$ even though recent evidence have also identified obesity as a relevant risk factor for CKD development in adolescents. ${ }^{12,13}$ Moreover, among cancer patients, renal impairment is quite common and is related to the cancer treatments and/or to the disease itself. ${ }^{14}$

Pain is a very common symptom among CKD patients, ${ }^{7}$ with musculoskeletal pain being predominant. Patients with end-stage renal disease (ESRD) suffer from tremendous symptom burden ${ }^{15}$ and the prevalence of pain reaches about $70 \%{ }^{16}$ They often need supportive or palliative care, highlighting that in renal failure conditions the painful component is an aspect not to be underestimated. ${ }^{7,17-19}$ Similarly, in children with CKD, pain, depression, anxiety, and fatigue are the most common complains. ${ }^{20}$

In the more advanced forms of renal failure, defined as ESRD, the substitution therapy, consisting of hemodialysis (HD), peritoneal dialysis, and kidney transplantation, may be necessary. In the last few years the number of patients receiving renal replacement therapy (RRT) has dramatically increased. ${ }^{21}$ In 2017, according to the ERA-EDTA Registry, in Europe, 127 ESRD patients per million people (pmp) began RRT, and the overall unadjusted prevalence of patients receiving RRT was 854 pmp. ${ }^{22}$ In the United States (US), according to the US Renal Data System 2019 Annual Data report, the trend in prevalence of recognized CKD has dramatically increased in the last 20 years, with 124,500 newly reported cases of ESRD in 2017, corresponding to a rate of $370.2 \mathrm{pmp}$ in the US population. The prevalence of ESRD in 2017 was 2204 pmp, corresponding to about three times that recorded in Europe, with $62.7 \%$ receiving HD therapy. ${ }^{23}$

Pain is one of the most common symptoms among patients undergoing HD, reaching a percentage of about $90 \%$ of treated subjects. ${ }^{7,24-26}$ Over $50 \%$ of these patients experience moderate-to-severe pain, which often is not adequately managed; moreover, pain may be associated with other comorbidities that significantly affect quality of life, such as depression and altered sleep patterns. Patients undergoing HD also reported anxiety, drowsiness, fatigue, nausea, dry mouth, loss of appetite, itch, and breathlessness. ${ }^{21}$ Pain may render patients unable to endure full HD sessions and increases the likeliness of withdrawal from dialysis. ${ }^{27}$

Pain is often underestimated and undertreated in patients with CKD or ESRD. ${ }^{7}$ When pain intensity requires a strong analgesic, opioids are indicated in the pharmacological recommendations for pain management in CKD adults, as a part of the analgesic therapeutic plan.7,9,28 However, in these specific patients, opioids may not exhibit the same safety profile as in the general population; therefore, there is still a lack of clinical consensus about their appropriate use in CKD subjects. Moreover, most of non-pain specialists may be unfamiliar with this kind of drugs and pain specialists are only occasionally involved in the management of these patients. Therefore, chronic pain in CKD and HD patients is often undertreated. According to the literature, almost $75 \%$ of HD patients with moderate to severe pain do not receive appropriate analgesia. ${ }^{29}$ Despite opioids are still a mainstay in the management of severe chronic pain, there are numerous barriers to their use in HD patients, such as fear about opioid-related adverse events, inadequate medical education, lack of training among nephrologists in pain management, and, finally, the paucity of clinical trials evaluating the use of opioids in HD patients. ${ }^{30}$

Unfortunately, the net result of the inadequate pain management by physicians is the increasing number of patients who use pain killers in auto-medication. Nonsteroid anti-inflammatory drugs (NSAIDs) are the most commonly used medications without a prescription at home, ${ }^{7}$ with significantly increased risks for the health of CKD and HD patients.

Finally, renal failure is a common finding in the late stage of cancer disease; for this reason, oncologists often deal with CKD patients. Opioids continue to be the cornerstone of severe chronic pain management in cancer patients; therefore, a careful selection of most suitable molecule is mandatory to avoid unwanted side effects. ${ }^{31}$

The aim of this review is to provide a pharmacological and clinical update on the correct and safe use of opioids in CKD and HD patients.

\section{Pharmacological Update on Opioid Analgesics in CKD}

Exogenous opioids work as analgesics, by mimicking and potentiating a physiological endogenous modulating system, mediated by endorphins, and their activity on opioid receptors. Four seven-transmembrane $\mathrm{G}$ protein-coupled opioid receptors have been identified: $\mu$ (MOR), $\delta$ (DOR), k (KOR) and nociceptin opioid receptor (NOR or NOP). The four major families of endogenous ligands are: $\beta$-endorphins, enkephalins, dynorphins, and nociceptin/ orphaninFQ. Opioids inhibit neurotransmission by their activity on calcium and potassium channels. Opioid 
receptors on the primary afferent fibers (PAF) prevent calcium influx in the first-order neuron and further release of excitatory neurotransmitters, such as glutamate and substance P. On the other side of the synaptic cleft, in the dorsal horn, opioid receptors are also expressed by second-order neurons, where they activate $G$ protein gated inwardly rectifying potassium (GIRK) channels and induce post-synaptically hyperpolarization. ${ }^{32}$ The net result of these processes is an effective modulation of pain transmission and clinical relevant analgesia (Figure 1).

Opioids are conventionally distinguished into major opioids, also called "strong opioids", which include morphine, oxycodone, hydromorphone, methadone, fentanyl, buprenorphine and tapentadol, and minor or "weak" opioids such as codeine and tramadol. ${ }^{33}$ Buprenorphine and tapentadol have been recently classified as "atypical" opioids, because of their pharmacological peculiarities, particularly pharmacodynamics, that make them different from all the other molecules included in the big family of "traditional opioids".34,35
Renal failure strongly affects the pharmacokinetics of many drugs including opioids, with relevant effects on drug's metabolites and the parent compound. ${ }^{7}$ For instance, geriatric patients showed decreased liver and kidney function together with alterations in the adipose tissue composition, which modify the opioid pharmacokinetics and increase the risk of toxicity because of their metabolites accumulation. ${ }^{36}$ For all these reasons, the choice of an appropriate analgesic strategy for patients with advanced kidney disease appears to be quite complex.

One of the best available parameter of kidney function, to be used for drug and dose selection, is represented by the glomerular filtration rate (GFR), which is currently identified by the international guidelines as less than $60 \mathrm{~mL} / \mathrm{min}$ per $1.73 \mathrm{~m}^{2}$ in the CKD patients, ${ }^{37}$ and less than $15 \mathrm{~mL} / \mathrm{min}$ per $1.73 \mathrm{~m}^{2}$ in the ESRD patients. ${ }^{38}$ Albuminuria, defined as the albumin: creatine ratio $(\mathrm{ACR})>3 \mathrm{mg} / \mathrm{mmol}$, is the marker of kidney damage that has been included in the last CKD classification for appropriate patient risk stratification. ${ }^{38}$ Table 1 shows pharmacological characteristics of currently available opioids for chronic pain management. ${ }^{39,40}$ Table 2

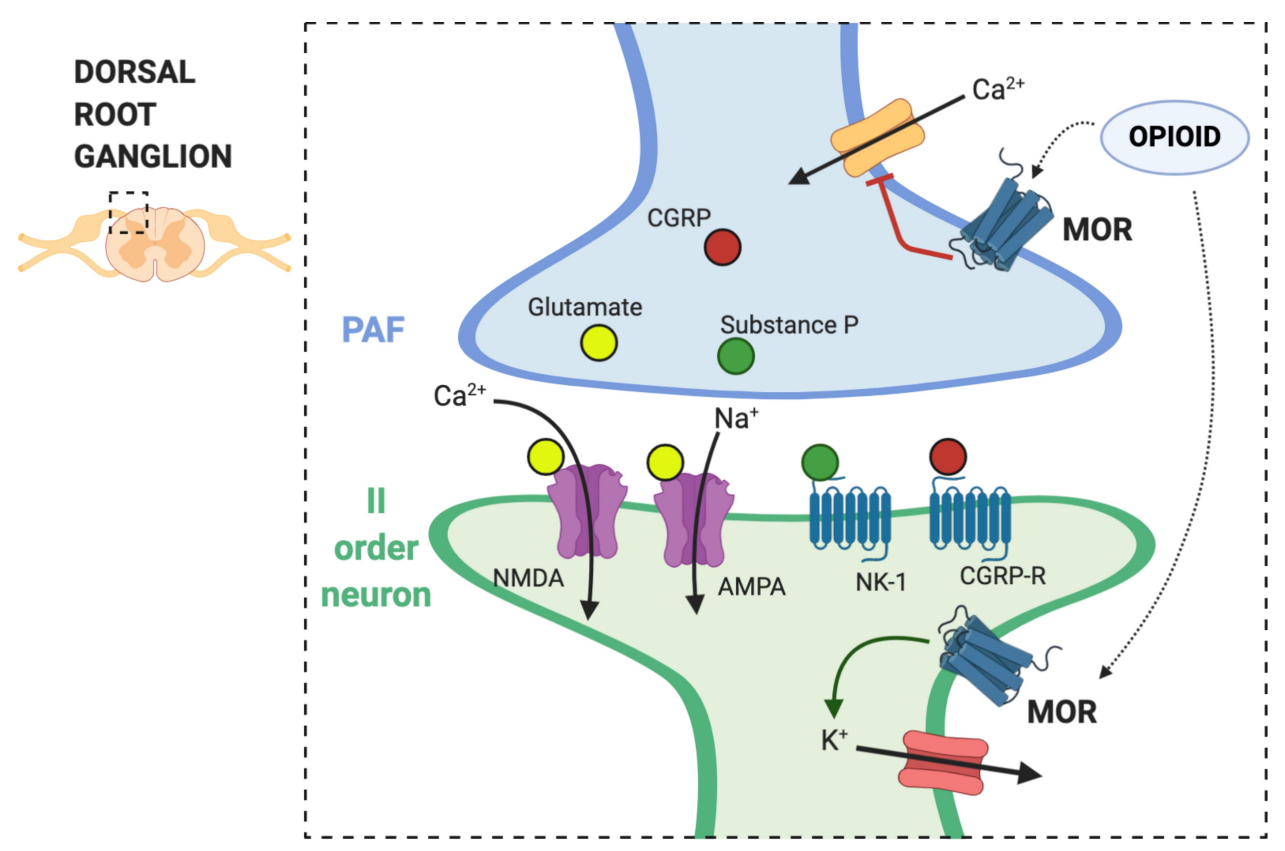

Figure I Mechanism of action of opioids on central sensitization. The dorsal root ganglion (DRG) is a group of cell bodies responsible for pain transmission from the primary afferent fibers (PAF), also known as nociceptors, and the central nervous system (CNS). Presynaptic neurons release glutamate, substance $P$, and calcitonin generelated protein (CGRP) in the synaptic cleft. On the post-synaptic neurons, also named second order neurons, glutamate activate two main receptors: the $\alpha$-amino-3hydroxy-5-methyl-4-isoxazolepropionic acid receptor (AMPA) and N-methyl-D-aspartate (NMDA) receptor. The flow of positive charged ions, calcium (Ca ${ }^{2+}$ ) and sodium $\left(\mathrm{Na}^{+}\right.$), through the NMDA and the AMPA receptors respectively, automatically leads pain signal to increase. Substance P, on the other hand, binds to the neurokinin-I (NKI) receptors, which leads to intracellular signaling that activate protein kinase $\mathrm{C}(\mathrm{PKC})$. This action removes the magnesium ion $\left(\mathrm{Mg}^{2+}\right)$ that physiologically blocks $\mathrm{NMDA}$ receptors; therefore, substance $P$ indirectly activates NMDA receptors and increases $\mathrm{Ca}^{2+}$ influx in the neurons, leading to increased neurotransmitter release. CGRP binds specific CGRP receptors on the second order neurons, leading to a change in receptor expression and function. All these mechanisms potentially contribute to central sensitization in chronic pain. Endogenous opioids and exogenous opioid agonists bind $\mu$ opioid receptors (MOR) in the pre- and post-synaptic neurons. Opioids close the voltage-gated calcium channels on the PAF and stop $\mathrm{Ca}^{2+}$ influx in the pre-synaptic neurons, where they reduce the release of glutamate, substance $\mathrm{P}$, and CGRP. In addition to that, binding of MOR on the post-synaptic neurons activate and open potassium channels, leading to an outflow of potassium ions ( $\left.\mathrm{K}^{+}\right)$and cellular hyperpolarization. Hyperpolarized second order neurons become less sensitive to excitatory inputs. 
Table I Pharmacology of Opioids for Chronic Pain Management ${ }^{39,40}$

\begin{tabular}{|c|c|c|c|c|c|}
\hline \multirow[t]{2}{*}{ Opioid } & \multicolumn{3}{|c|}{ Physico-Chemical Properties ${ }^{40}$} & \multirow[t]{2}{*}{ Metabolism ${ }^{39}$} & \multirow[t]{2}{*}{ Elimination ${ }^{39}$} \\
\hline & Vd (L/kg) & PPB (\%) & MW (g/mol) & & \\
\hline Buprenorphine & 8.3 & 96 & 467.6 & $\begin{array}{l}\text { Extensive first-pass hepatic metabolism. } \\
\text { Phase I metabolism via CYP3A4 and CYP3A5 to } \\
\text { norbuprenorphine. } \\
\text { Phase } 2 \text { metabolism via glucuronidation to the inactive } \\
\text { compounds B3G and N3G }\end{array}$ & $\begin{array}{l}\text { Metabolites are } \\
\text { primarily eliminated via } \\
\text { feces. } \\
\text { Only } 10-30 \% \text { of the } \\
\text { dose is excreted in } \\
\text { urine. }\end{array}$ \\
\hline Fentanyl citrate & 4 & $80-85$ & 336.5 & $\begin{array}{l}\text { Extensive hepatic metabolism into inactive } \\
\text { metabolites. } \\
\text { Phase I metabolism via CYP3A4 to norfentanyl (99\%) }\end{array}$ & $\begin{array}{l}<7 \% \text { excreted } \\
\text { unchanged in the urine. } \\
<1 \% \text { excreted } \\
\text { unchanged in the feces. }\end{array}$ \\
\hline $\begin{array}{l}\text { Hydromorphone } \\
\text { hydrochloride }\end{array}$ & 1.22 & 7.1 & 321.8 & $\begin{array}{l}\text { Extensive first-pass hepatic metabolism (62\%) } \\
\text { Phase } 2 \text { metabolism: Glucuronidation via UGT2B7 to } \\
\text { H3G with no analgesic activity (possibly causes } \\
\text { neuroexcitation, agitation, and confusion) } \\
\text { Minor Phase I metabolism via CYP3A4 and CYP2C9 } \\
\text { to norhydromorphone }\end{array}$ & $\begin{array}{l}\text { Mainly eliminated } \\
\text { through the urine as } \\
\text { H3G. } \\
7 \% \text { excreted unchangec } \\
\text { in the urine. } \\
1 \% \text { excreted unchangec } \\
\text { in the feces. }\end{array}$ \\
\hline $\begin{array}{l}\text { Oxycodone } \\
\text { hydrochloride }\end{array}$ & 2.6 & 45 & 405.9 & $\begin{array}{l}\text { Phase I metabolism: } \\
\text {-via CYP3A4 and CYP3A5 (N-demethylation) to } \\
\text { noroxycodone, and then via CYP2D6 to } \\
\text { noroxymorphone } \\
\text {-via CYP2D6 (O-demethylation) to oxymorphone, and } \\
\text { then via CYP3A4 to noroxymorphone }\end{array}$ & $\begin{array}{l}\text { Mainly eliminated } \\
\text { through the urine: } \\
23 \% \text { unbound } \\
\text { noroxycodone } \\
10 \% \text { conjugated } \\
\text { oxymorphone } \\
9 \% \text { free and conjugated } \\
\text { oxycodone } \\
<1 \% \text { oxymorphone }\end{array}$ \\
\hline Tramadol & 3 & 20 & 299.8 & $\begin{array}{l}\text { Extensive first-pass hepatic metabolism } \\
\text { Phase I metabolism: } \\
\text {-via CYP3A4 and CYP2B6 (N-demethylation) to N- } \\
\text { desmethyl-tramadol (M2) } \\
\text {-via CYP2D6 (O-demethylation) to O- } \\
\text { desmethyltramadol (MI) }\end{array}$ & $\begin{array}{l}90 \% \text { excreted in the } \\
\text { urine ( } 30 \% \text { as } \\
\text { unchanged drug) } \\
10 \% \text { excreted in the } \\
\text { feces }\end{array}$ \\
\hline $\begin{array}{l}\text { Tapentadol } \\
\text { hydrochloride }\end{array}$ & 6.7 & 20 & 221.3 & $\begin{array}{l}\text { Phase } 2 \text { metabolism via glucuronidation (97\%). } \\
\text { Minor contribution of Phase I metabolism via } \\
\text { CYP2C9 (I3\%) to N-desmethyl tapentadol and } \\
\text { CYP2D6 (2\%) to hydroxyl tapentadol. } \\
\text { All metabolites are inactive. }\end{array}$ & $\begin{array}{l}99 \% \text { renal excretion of } \\
\text { tapentadol and its } \\
\text { metabolites. } \\
3 \% \text { excreted in urine as } \\
\text { unchanged drug. }\end{array}$ \\
\hline Methadone & $2-6$ & $60-90$ & 309.5 & $\begin{array}{l}\text { Extensive first-pass hepatic metabolism into inactive } \\
\text { metabolites. } \\
\text { N-demethylation } \\
\text { Metabolism by different CYP450 enzymes: } \\
\text { CYP2C19, CYP3A7, and CYP2C8 preferentially } \\
\text { metabolize (R)-methadone; CYP2B6, CYP2D6, and } \\
\text { CYP2C18 preferentially metabolize (S)-methadone; } \\
\text { CYP3A4 does not have an enantiomer preference }\end{array}$ & $\begin{array}{l}\text { Excreted in the feces } \\
\text { and urine after } \\
\text { extensive } \\
\text { biotransformation. } \\
20 \% \text { excreted } \\
\text { unchanged in the urine. }\end{array}$ \\
\hline
\end{tabular}

(Continued) 
Table I (Continued).

\begin{tabular}{|c|c|c|c|c|c|}
\hline \multirow[t]{2}{*}{ Opioid } & \multicolumn{3}{|c|}{ Physico-Chemical Properties 40} & \multirow[t]{2}{*}{ Metabolism ${ }^{39}$} & \multirow[t]{2}{*}{ Elimination ${ }^{39}$} \\
\hline & Vd (L/kg) & PPB (\%) & MW (g/mol) & & \\
\hline $\begin{array}{l}\text { Morphine } \\
\text { sulphate }\end{array}$ & 3.2 & 35 & 758.8 & $\begin{array}{l}\text { Phase } 2 \text { metabolism via glucuronidation by UGT2B7 } \\
\text { (90\%) to: } \\
\text {-M3G without analgesic activity, but possibly } \\
\text { neurotoxic } \\
\text {-M6G with analgesic activity. } \\
\text { Minor conversion to normorphine. }\end{array}$ & $\begin{array}{l}70-80 \% \text { excreted in the } \\
\text { urine } \\
10 \% \text { excreted in the } \\
\text { feces } \\
<10 \% \text { excreted in urine } \\
\text { as unchanged drug. }\end{array}$ \\
\hline Codeine & 2.6 & 7 & 406.4 & $\begin{array}{l}\text { Phase } 2 \text { metabolism via glucuronidation by UGT2B7 } \\
\text { and UGT2B4 ( } 80 \%) \text { to C6G } \\
\text { Phase I metabolism: } \\
\text {-via CYP3A4 ( } \mathrm{N} \text {-demethylation) to norcodeine (10\%) } \\
\text { without analgesic properties } \\
\text {-via CYP2D6 (O-demethylation) to morphine }(5-10 \%)\end{array}$ & $\begin{array}{l}90 \% \text { excreted by } \\
\text { kidneys } \\
10 \% \text { excreted in urine } \\
\text { as unchanged drug. }\end{array}$ \\
\hline
\end{tabular}

Abbreviations: Vd, volume of distribution; PPB, plasma protein binding; WS, water solubility; MW, molecular weight; B3G, buprenorphine-3-glucuronide; N3G, norbuprenorphine-3-glucuronide; H3G, hydromorphone-3-glucuronide; H6G, hydromorphone-6-glucuronide; C6G, codeine-6-glucuronide.

Notes: Green: safe use in CKD; Yellow: use with caution in CKD; Orange: not recommended in CKD

resumes clinical information on their use in different stages of CKD and during HD.

Morphine is one of the most effective MOR agonist for the treatment of severe pain. It is still the first-choice drug in managing severe chronic cancer pain. ${ }^{31}$ In the liver, morphine is metabolized into two primary metabolites named 3 (M3G) and 6 glucuronide (M6G), which are eliminated via kidney pathways. In CKD condition, a significant renal retention of active or toxic metabolites occurs; for this reason, morphine is contraindicated in cases of renal failure, because the M6G accumulation may cause neurotoxic symptoms. ${ }^{7,41-43}$ Codeine is a prodrug, which is metabolized in the liver into morphine through the action of cytochrome P450 2D6 (CYP2D6). Since codeine forms the same morphine metabolites excreted by kidney, it may evoke the same side effects in CKD patients. ${ }^{7,45}$ Moreover, the risk of neurotoxic symptoms also depends by the patients' genetic pattern, because subjects identified as ultra-rapid metabolizers may produce morphine very quickly. ${ }^{46}$ Therefore, an analgesic approach with morphine or codeine is not specifically recommended in patients with renal impairment. Based on this first evaluation, it is evident that the WHO analgesic ladder needs to be adapted for CKD patients, 9,44 since morphine and codeine are not recommended for subjects with GFR value lower than $60 \mathrm{~mL} / \mathrm{min}$ per $1.73 \mathrm{~m}^{2,34,41,47}$ and should not be used at all in ESRD subjects. ${ }^{28,48,49}$

Notwithstanding the contraindications related to the use of the above-mentioned opioids, the use of oxycodone, tramadol, hydromorphone or methadone is approved in this sub-population, but they need specific dosing adjustments. $^{30}$ A dose reduction, a greater interval between doses, compared with classic analgesic regimens, and a careful monitoring of the patients are strongly recommended. ${ }^{7}$

For instance, given its greater liposolubility compared to morphine, oxycodone shows a faster action and a greater analgesic effect, thus it is widely used for chronic pain treatment. In fact, it seems to have a good analgesic efficacy in chronic pain conditions with minor hallucination and mental confusion, as side effects. ${ }^{50}$ Samolsky Dekel et $\mathrm{al}^{51}$ tested the efficacy and safety of oxycodone treatment in two groups of dialyzed patients suffering from ESRD. Data reported in this study suggested the safety of using oxycodone in HD patients, ${ }^{51}$ even though it remains a second-line agent compared with other opioids endowed of safer renal profile. ${ }^{7,52}$ Oxycodone is likely to be removed during HD, because of its low molecular weight and limited volume of distribution. Indeed, although less than $10 \%$ is excreted unchanged in urine, oxycodone prescription, in CKD patients, needs careful monitoring: its hepatic metabolism produces multiple metabolites, including the noroxycodone and oxymorphone (further metabolized to noroxymorphone), which could accumulate in patients with renal failure, since oxycodone elimination is relatively impaired in ESRD patients. ${ }^{52}$ Peak plasma concentrations $50 \%$ higher than normal subjects have been observed in patients suffering from renal failure. ${ }^{53}$ 
Table 2 Clinical Use of Opioids for Chronic Pain Management in CKD and HD Patients ${ }^{28,30,39}$

\begin{tabular}{|c|c|c|c|c|c|}
\hline Opioid & $\begin{array}{l}\text { Route of } \\
\text { Administration }\end{array}$ & $\begin{array}{l}\text { Starting } \\
\text { Dosage }\end{array}$ & Indications & Clinical Use in $C K D^{30}$ & $\begin{array}{l}\text { Dializability and Clinical Use in } \mathbf{H D}^{28} \text {, } \\
39\end{array}$ \\
\hline Buprenorphine & $\begin{array}{l}\text { Transdermal } \\
\text { patch } \\
7 \text { days } \\
4 \text { days }\end{array}$ & $\begin{array}{l}5-20 \mathrm{mcg} / \mathrm{h} \\
\geq 35 \mathrm{mcg} / \mathrm{h}\end{array}$ & $\begin{array}{l}\text { Severe } \\
\text { chronic pain }\end{array}$ & $\begin{array}{l}\text { Safer profile. } \\
\text { No dosage adjustment } \\
\text { required at any stage of } \\
\text { CKD. }\end{array}$ & $\begin{array}{l}\text { Not removed by HD. } \\
\text { No dosage adjustment required. }\end{array}$ \\
\hline Fentanyl citrate & $\begin{array}{l}\text { Transdermal } \\
\text { patch } \\
3 \text { days }\end{array}$ & $\geq 12 \mathrm{mcg} / \mathrm{h}$ & $\begin{array}{l}\text { Severe } \\
\text { chronic pain }\end{array}$ & $\begin{array}{l}\text { Safer profile. } \\
\text { No clinically significant } \\
\text { accumulation in CKD. }\end{array}$ & $\begin{array}{l}\text { PK characteristics do not favor removal by } \\
\text { HD. } \\
\text { Clearance depends on filter, flow rate and } \\
\text { type of dialysis. } \\
\text { It could be absorbed by CTI } 90 \text { dialysis } \\
\text { membranes. }\end{array}$ \\
\hline $\begin{array}{l}\text { Hydromorphone } \\
\text { hydrochloride }\end{array}$ & Oral & $\geq 4 \mathrm{mg}$ OD & $\begin{array}{l}\text { Severe } \\
\text { chronic pain } \\
\text { (second line } \\
\text { treatment) }\end{array}$ & $\begin{array}{l}\text { Use with caution, with } \\
\text { close monitoring. } \\
\text { Dose adjustment required } \\
\text { in renal failure*: } \\
\text { - Mild: } 100 \% \text { normal dose } \\
\text { - Moderate: } 50 \% \text { normal } \\
\text { dose } \\
\text { - Severe: } 25 \% \text { normal } \\
\text { doselncrease dosing } \\
\text { intervals as needed. }\end{array}$ & $\begin{array}{l}\mathrm{H} 3 \mathrm{G} \text { accumulates between dialysis } \\
\text { treatments. } \\
\text { Easily dialyzed: } 60 \% \text { removed by HD. } \\
\text { Sudden decreases in opioid concentrations } \\
\text { may result in withdrawal symptoms. } \\
\text { Post-dialysis supplemental dosing could be } \\
\text { required, but no clinical data are available. }\end{array}$ \\
\hline $\begin{array}{l}\text { Oxycodone } \\
\text { hydrochloride }\end{array}$ & Oral & $\geq 5 \mathrm{mg}$ BID & $\begin{array}{l}\text { Severe } \\
\text { chronic pain } \\
\text { (second line } \\
\text { treatment) }\end{array}$ & $\begin{array}{l}\text { Use with caution, with } \\
\text { close monitoring. } \\
\text { Dose adjustment required } \\
\text { in renal failure: } \\
\text { - Mild: } 50 \% \text { normal dose } \\
\text { - Moderate: } 25-50 \% \text { nor- } \\
\text { mal dose } \\
\text { - Severe: } \\
\text { contraindicatedlncrease } \\
\text { dosing intervals as } \\
\text { needed. }\end{array}$ & $\begin{array}{l}\text { Oxycodone and its active metabolite, } \\
\text { noroxycodone, are removed by HD. } \\
\text { Oxycodone has been used in dialysis- } \\
\text { dependent patients, and it is well-tolerated, } \\
\text { without need for opioid compensation. }\end{array}$ \\
\hline Tramadol & Oral & $\begin{array}{l}\geq 50 \mathrm{mg} \\
\mathrm{BID}\end{array}$ & $\begin{array}{l}\text { Severe } \\
\text { chronic pain } \\
\text { (second line } \\
\text { treatment) }\end{array}$ & $\begin{array}{l}\text { Use with caution, with } \\
\text { close monitoring. } \\
\text { Dose adjustment required } \\
\text { in renal failure: } \\
\text { - Mild: } 100 \% \text { normal dose } \\
\text { - Moderate: } 50 \% \text { normal } \\
\text { dose } \\
\text { - Severe: } 50 \% \text { normal } \\
\text { doselncrease dosing } \\
\text { intervals as needed. }\end{array}$ & $\begin{array}{l}\text { Significantly removed by hemodialysis. } \\
\text { Re-dosing after a HD session may be } \\
\text { necessary. }\end{array}$ \\
\hline $\begin{array}{l}\text { Tapentadol } \\
\text { hydrochloride }\end{array}$ & Oral & $\begin{array}{l}\geq 25 \mathrm{mg} \\
\text { BID }\end{array}$ & $\begin{array}{l}\text { Severe } \\
\text { chronic pain } \\
\text { (second line } \\
\text { treatment) }\end{array}$ & $\begin{array}{l}\text { No dose adjustment } \\
\text { required for mild to } \\
\text { moderate renal failure. } \\
\text { No data available for } \\
\text { severe CKD. }\end{array}$ & $\begin{array}{l}\text { Data not available in HD. } \\
\text { It is likely to be dialyzed to some extent, } \\
\text { because of its low protein binding, low } \\
\text { molecular weight, and average water } \\
\text { solubility. }\end{array}$ \\
\hline
\end{tabular}

(Continued) 
Table 2 (Continued).

\begin{tabular}{|c|c|c|c|c|c|}
\hline Opioid & $\begin{array}{l}\text { Route of } \\
\text { Administration }\end{array}$ & $\begin{array}{l}\text { Starting } \\
\text { Dosage }\end{array}$ & Indications & Clinical Use in $\mathbf{C K D}^{30}$ & $\begin{array}{l}\text { Dializability and Clinical Use in } H^{28} \text {, } \\
39\end{array}$ \\
\hline Methadone & Oral & $\begin{array}{l}\mathrm{I}-2 \mathrm{mg} \\
\text { BID }\end{array}$ & $\begin{array}{l}\text { Severe } \\
\text { chronic pain } \\
\text { Mainly for } \\
\text { MMT }\end{array}$ & $\begin{array}{l}\text { Use only when other } \\
\text { opioids are } \\
\text { contraindicated. } \\
\text { Dose reduction may be } \\
\text { required in ESRD because } \\
\text { its half-life is very } \\
\text { long and unpredictable, } \\
\text { therefore } \\
\text { toxicity may be delayed }\end{array}$ & $\begin{array}{l}\text { Methadone and its metabolites are not } \\
\text { removed by HD. } \\
\text { No supplemental doses are required after a } \\
\text { HD session. } \\
\text { Check Q-T interval. Arrhythmias may be } \\
\text { exacerbated by potassium and magnesium } \\
\text { reduction after HD. }\end{array}$ \\
\hline Morphine sulphate & \multicolumn{5}{|c|}{ Not recommended due to metabolites accumulation. To be avoided in CKD and HD patients. } \\
\hline Codeine & \multicolumn{5}{|c|}{ Not recommended due to metabolites accumulation. To be avoided in CKD and HD patients. } \\
\hline
\end{tabular}

Notes: *Mild: Creatinine Clearance 60 to $<90 \mathrm{~mL} / \mathrm{min}$; Moderate: Creatinine Clearance 30 to $<60 \mathrm{~mL} / \mathrm{min}$; Severe: Creatinine Clearance 15 to $<30 \mathrm{~mL} / \mathrm{min}$. Green: safe use in CKD; Yellow: use with caution in CKD; Orange: not recommended in CKD.

Abbreviation: MMT, methadone maintenance treatment.

With the regard to the use of the "weak opioid" tramadol, it is relevant to point out that $90 \%$ is renally excreted and its half-life may increase up to twofold in CKD patients. ${ }^{44,54}$ Currently the use of tramadol for pain management in children younger than 12 years is contraindicated. ${ }^{9}$ In contrast, elderly patients with GFR > $30 \mathrm{~mL} / \mathrm{min}$ per $1.73 \mathrm{~m}^{2}$ can assume tramadol and do not need dosage adjustments, ${ }^{55}$ even though those $>75$ years old should not exceed the dosage of $300 \mathrm{mg}$; whereas patients with a creatinine clearance $<30 \mathrm{~mL} / \mathrm{min}$ should be treated using the dose of 50-100 mg tramadol, increasing dosing interval with a maximum daily dose of 200 mg. ${ }^{7,55}$ HD significantly removes tramadol, thus its administration should be given after each HD session. ${ }^{7,56}$ Two case reports have been published on tramadol-induced respiratory depression in HD patients, both caused by accidental overdoses. ${ }^{30}$

Hydromorphone is about 5 times more potent than morphine and does not have the metabolite 6-glucuronide, which is responsible of the analgesic and central nervous system (CNS) depressive activity. A prospective, openlabel, observational study conducted in 2008 showed that hydromorphone does not accumulate, probably because of its rapid conversion into hydromorphone-3-glucuronide (H3G) metabolite. Indeed, H3G could be accumulated in patients with low GFR $\left(<10 \mathrm{~mL} / \mathrm{min} / 1.73 \mathrm{~m}^{2}\right)$ causing myoclonus and delirium ${ }^{57,58}$ and, moreover, $\mathrm{H} 3 \mathrm{G}$ can be accumulated between dialysis sessions probably triggering a greater sensory-type pain and a reduced duration of analgesia. $^{59}$ Based on the experimental evidence, hydromorphone seems to be exempt from adverse effects when it is used at standard doses in the renal failure population $^{53}$ and appear to be quite safe in dialyzed

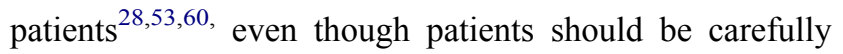
monitored. ${ }^{7,28,61}$

Methadone, mainly used for maintenance treatment in opiate dependence, is excreted in the feces and it appears quite safe for the use in CKD condition, since plasma concentrations in these patients are similar with those observed in control subjects. ${ }^{7,28,62}$ Moreover, methadone has moderate water solubility and low molecule weight suggesting that it can be poorly removed by hemodialysis. ${ }^{28,63}$

Patients with a severe impairment of glomerular filtration can be treated with fentanyl, sufentanil, buprenorphine, and tapentadol, which appear to have a safer renal profile. $^{28,49,64}$

Fentanyl is mostly metabolized and eliminated in the liver and none of its metabolites seems to be active, ${ }^{65}$ even though some evidence suggests that the parental compound can be accumulated in CKD patients. ${ }^{28}$ Different studies demonstrated its safety profile in renal failure conditions, ${ }^{28,66,67}$ at least in the short term, ${ }^{28}$ highlighting that fentanyl infusion over 2 days have a satisfying pain control and does not promote adverse reactions. ${ }^{68}$ Because of high protein binding, high volume of distribution and low water solubility, fentanyl is not appropriate in dialyzed patients, ${ }^{28,69,70}$ as well as sufentanil. Transdermal fentanyl patches, however, have been successfully used in HD patients without significant side effects, even at high dose (up to $500 \mathrm{mcg} / \mathrm{h}$ ) and for long-term therapy (up to 
3 years). These data come from a case series, while no specific clinical trials are available in HD patients. ${ }^{71}$

Buprenorphine appears to be particularly useful for the management of severe chronic pain in CKD patients, ${ }^{72,73}$ firstly because it does not produce active metabolites that can be accumulated promoting toxic effects. Indeed, buprenorphine is metabolized in the liver producing two metabolites: buprenorphine-3-glucuronide (B3G) and norbuprenorphine-3-glucuronide $(\mathrm{N} 3 \mathrm{G})$ which are mainly excreted via bile. ${ }^{74}$ Some studies evaluated whether renal dysfunction could have some effect on the buprenorphine clearance, showing that this parameter was similar in patients with normal and impaired renal function.,72 Moreover, the efficacy and safety of buprenorphine in severe renal dysfunction without dose adjustment make it well suited for chronic pain management in elderly and kidney impaired individuals including those requiring HD. $^{71,75,76}$

The innovative analgesic drug tapentadol is a chemical entity endowed of dual and synergistic mechanisms of action: MOR receptor agonist and noradrenaline reuptake inhibitor (NRI) (MOR-NRI). ${ }^{77}$ Among the main features of this molecule, it is worth noting that its metabolism on Phase II produces inactive metabolites, which do not show analgesic activity, making this analgesic a safe and efficacy compound in patients with renal failure. ${ }^{78,79}$ Clinical trials on the tapentadol extended release (ER) formulation showed that, in the range of 100-200 $\mathrm{mg}$ twice daily, dosage adjustments are not required in mild-to-moderate renal impairment conditions. ${ }^{79}$ Long-term therapy did not show association with clinically significant changes in laboratory values, including hepatic and renal parameters.-

${ }^{80}$ Moreover, tapentadol ER is indicated as first choice opioid for the treatment of chronic painful diabetic neuropathy, which is a common comorbidity with $\mathrm{CKD} .{ }^{5,7}$ No data are available on the use of tapentadol in ESRD and HD patients.

\section{Epidemiology of Opioids Use in CKD and HD Patients}

CKD and HD patients are often affected by severe chronic pain; therefore, they are expected to require strong analgesics more frequently than other people. ${ }^{81}$ Notwithstanding this evidence, opioid use in CKD and HD patients is significantly lower than that recorded in the general population, probably because of concerns about reduced clearance and increased adverse effects. ${ }^{42}$
According to the clinical studies published between 1995 and 2004, the prevalence of opioid use in HD patients in different countries ranged from $5 \%$ to $36 \%$. In this percentage, patients with long-term dialysis were more likely to receive opioid prescriptions when they also exhibited cancer, cardiovascular disease, and psychiatric disorders. ${ }^{82}$

Using the 2006-2010 United States (US) Renal Data System information, over $20 \%$ (ranging from $9.5 \%$ to $40.6 \%$ ) of HD patients received chronic ( $\geq 90$-day) opioid supply, and over $60 \%$ received at least one opioid prescription. Opioid prescription was positively correlated with gender (women), age (young or middle-aged), race (caucasic), social status (nursing home residents), disease (cancer), and pain-related hospitalizations. In 2010, hydrocodone $(11.7 \%)$ and oxycodone $(5.4 \%)$ were the most commonly prescribed opioids, followed by tramadol $(2.5 \%)$ and propoxyphene $(1.4 \%){ }^{83}$ This trend changed after the withdrawal of propoxyphene from the US market in 2010, with a significant increase in the use of more potent opioids. ${ }^{81}$

These "real life" data are confounding for physicians approaching patients with CKD. According to pharmacological data, indeed, hydrocodone and oxycodone are not the first-line drugs for patients with severe renal impairment; however, as they are the most commonly prescribed opioids in the general population, accounting respectively for 51 and $16 \%$ of total prescriptions, they are also the most commonly used in HD patients. ${ }^{84}$ Conversely, buprenorphine, which is considered the safest opioid to be used in HD patients, is completely absent in the US data. ${ }^{83}$

It is relevant to point out that most studies did not examine the reasons for analgesic drug prescription in this population. Only one over 10 studies, indeed, examined the reasons for opioid prescription, where the musculoskeletal pain was the most common diagnosis (65\%). Therefore, data on the prescribing appropriateness of opioids in patients suffering from CKD are lacking.

These observations reflect the urgent need for medical education in dialysis providers. Probably in the future, concerns about the use of NSAIDs and increased knowledge about pathophysiology of chronic pain will make physicians more confident with the use of major analgesics and opioid prescriptions, which are supposed to increase and to be more appropriated.

Finally, insufficient evidence exists on the safety and efficacy of opioids in pediatric CKD patients. ${ }^{9}$ In general, most opioids are only prescribed off-label in the pediatric setting and 
approved molecules vary in Europe and in the US. In patients, younger than 12 years old, codeine prescription has been recently restricted by FDA and EMA; while tramadol is currently contraindicated only in the US, while in Europe it is approved by EMA in children older than 1 year. Low dosage transdermal fentanyl is also used in children older than 2 years, while oxycodone has been approved by FDA, only in 2016, for use by children between 11 and 16 years old, when alternative treatments are not effective for adequate pain management. Transdermal buprenorphine has been used in children in the palliative care setting, but evidence is still very limited. Morphine and hydromorphone are not approved in the pediatric population in the US. Nowadays, in Europe, tapentadol oral solution is the only drug that underwent a specific multinational pediatric development program in children aged 2 to $<8$ years, but it is still not approved in the US. ${ }^{85}$ All these limitations make the management of severe chronic pain in children very challenging for physicians.

\section{Appropriate Opioid Use in CKD and HD Patients}

The role of opioids in chronic pain management is well defined by clinical recommendations; however, the current opioid crisis recorded in the US rose the need for a better identification of a "rationale use of opioids", particularly in chronic noncancer pain management. The European situation is nowadays different compared with the opioid epidemic in the US. ${ }^{86}$ However, general rules on the safe and appropriate opioid use have been introduced in the context of an adequate multidisciplinary pain management ${ }^{87}$ (Table 3 ) and are also applicable to the CKD setting.

CKD and HD patients certainly show greater fragility than the general population; however, few indications are currently available in literature on the proper use of opioids in this context. As for many other medications, the outcome of the analgesic treatment is directly related with the prescribing appropriateness.

Drug therapy appropriateness is primary based on the identification of the pathogenetic mechanism underlying pain. Physicians should be encouraged to make an accurate pain diagnosis, which includes not only pain intensity, but also pain quality. Chronic pain is the result of complex neuroplasticity phenomena that induce functional and structural modifications of the central nervous system (CNS). Therefore, the use of central analgesics, such as opioids, in chronic pain management is essential to control such mechanisms underlying CNS plasticity. ${ }^{88}$ Identifying the etiology of pain, through an
Table 3 Safe and Appropriate Use of Opioids in Chronic Pain Management ${ }^{87}$

\begin{tabular}{|c|c|}
\hline I & Patient should be selected and regularly assessed \\
\hline 2 & Non-pain specialists need access to expert advice \\
\hline 3 & Opioids should be prescribed by competent doctors \\
\hline 4 & The correct dose is the lowest possible dose \\
\hline 5 & Clear treatment goals should be agreed with the patients \\
\hline 6 & $\begin{array}{l}\text { Close on-going patient supervision is recommended to reassess } \\
\text { the benefits and risks of continued therapy }\end{array}$ \\
\hline 7 & $\begin{array}{l}\text { Opioids should be tapered down or discontinued, if benefits do } \\
\text { not outweigh risks }\end{array}$ \\
\hline 8 & $\begin{array}{l}\text { Patients and their families should be educated on safe opioid use } \\
\text { and storage }\end{array}$ \\
\hline 9 & $\begin{array}{l}\text { Patients should be made aware of the potential for misuse, } \\
\text { abuse and addiction }\end{array}$ \\
\hline 10 & Signs of addictive behavior should be monitored and addressed \\
\hline II & Opioids should be dispensed by competent pharmacists \\
\hline
\end{tabular}

accurate physical examination, is a key factor for prescribing a mechanism-based treatment. Most chronic pain syndromes are, indeed, characterized by "mixed pain" for the coexistence of nociceptive and neuropathic components of pain. Neuropathic pain (NP) is often unresponsive to the traditional MOR agonists as a single therapy. When the neuropathic component is prevalent or exclusive, such as in patients suffering from painful diabetic peripheral neuropathy (PDPN), first line drugs are anticonvulsants and antidepressants, while opioids should be used as an add-on therapy, only in those patients who do not respond to traditional adjuvants. Conversely, in nociceptive pain, opioids are highly effective, even when administered in mono-therapy, and represent the strongest available analgesics. Among strong analgesics, tapentadol, due to its dual mechanism of action, is considered the first-line opioid in patients with neuropathic pain conditions, which may be very common among CKD patients, such as PDPN, ${ }^{89}$ or mixed pain syndromes, such as back pain ${ }^{90}$ or cancer pain. $^{91}$

Different conditions may cause chronic pain in CKD patients. Pain can be unrelated to the renal disease (mainly musculoskeletal pain conditions), may result from primary kidney disease, or may be a complication of HD therapy. ${ }^{30}$ CKD patients exhibit a variety of painful conditions, which may be nociceptive or neuropathic in nature. Indeed, in these patients, nociceptive pain may include osteoarthritis, ${ }^{92}$ renal osteodystrophy, dialysis-related amyloid arthropathy, ${ }^{93}$ and kidney or liver capsule distension from autosomal dominant polycystic kidney disease (ADPKD). ${ }^{94}$ On the other hand, many CKD patients may suffer from NP conditions. Being 
diabetes the most common reason of ESRD, PDPN is the most common NP syndrome among HD patients. ${ }^{5}$ Other patients may suffer from mixed chronic pain conditions, such as low back pain (LBP) and cancer pain. Conversely, dialysis-related amyloidosis (DRA) may cause both a NP condition, such as carpal tunnel syndrome, ${ }^{95}$ or a mainly nociceptive pain, such as frozen shoulder, caused by scapula-humeral peri-arthritis. Ischemic pain is also very common among HD patients, due to vasculitis and calciphylaxis, as the result of altered calcium and phosphate metabolism. In critical limb ischemia, invasive techniques of pain management, such as spinal cord stimulation (SCS) could be appropriate, ${ }^{96}$ but unfortunately data on HD patients are still lacking.

Intradialytic pain should be distinguished from other types of pain in CKD patients. It is mainly related to the vascular access. More recent the arteriovenous fistula (AVF), more common and severe is the pain associated with cannulation, steal syndrome and central vein stenosis. ${ }^{97}$ Headache and abdominal pain are also common during HD. Dialysis-related headache affects up to $50 \%$ of patients and resolves within 72 hours. ${ }^{98}$ The most common medication used for intradialytic pain is IV paracetamol.

\section{Side Effects of Opioids in CKD and HD Patients}

In chronic pain management, opioids tolerability is often affected by gastrointestinal side effects, such as nausea, vomiting, and constipation, and many other side effects, including dizziness, somnolence, urinary retention, dry mouth, and hormonal abnormalities. ${ }^{99}$

Respiratory depression is the most feared adverse event following opioids administration, because it can be life-threatening; however, it is very uncommon in chronic pain management, and is mainly related to pre-existing comorbidities, which may increase the risk, or to inadequate accidental doses. Among HD patients few cases have been described. ${ }^{30}$ In emergency situations, when a patient breathing is slowdown or stopped due to an opioid overdose, naloxone can be administrated, at the initial dose of $0.4 \mathrm{mg}$ to $2 \mathrm{mg} \mathrm{IV}$, and repeated at 2 to 3 minute intervals, if desired response is not obtained. Naloxone is an opioid antagonist that temporarily stop the opioid effect and quickly restore normal breathing. However, due to the short half-life, the duration of action of some opioids may exceed that of naloxone; therefore, repeated doses may be needed and monitoring of vital parameters is strongly recommended.
Opioid induced constipation (OIC) is the most common and persistent side effect in opioid users. MOR are extensively distributed in the gastrointestinal (GE) tract and physiologically modulate gut motility and water absorption. Opioids, by activating MOR in the enteric nervous system, significantly decrease gut motility, through the myenteric plexus, and inhibit ions and water secretion the GE lumen, through their activity in the submucosal plexus. Patients do not develop tolerance to OIC; therefore, it requires treatment over time. Beyond common laxative drugs, in the last decade, peripherally-acting muopioid receptor antagonists (PAMORA) have been introduced in the market (Table 4). These compounds exert their antagonist activity only in the enteric nervous system, because of their inability to cross the blood brain barrier. ${ }^{100}$

A few data are available on PAMORAs use in CKD patients. Naloxegol, a PEGylated derivative of naloxone, was generally well tolerated in patients with moderate or severe renal function, when administrated in the single $25 \mathrm{mg}$ dose. Due to the low molecular weight, naloxegol is efficiently cleared by HD. ${ }^{101}$ However, in subjects with moderate to severe renal impairment, the starting dose should be reduced to $12.5 \mathrm{mg}$. Conversely, the pharmacokinetics of the naltrexone derivative, naldemedine, at the standard dose of $0.2 \mathrm{mg}$ daily, in patients with mild, moderate or severe renal impairment, are comparable with those in normal subjects; therefore, dose adjustments are not required. ${ }^{100}$ Its use in a renal impairment subgroup analysis was effective and safe at the dosage of 0.2 $\mathrm{mg}$ daily, consistent with the overall population. ${ }^{102}$ Naloxegol and naldemedine are orally administered and are primarily metabolized via CYP450 pathways. Physician should be aware that accumulated uremic toxins in CKD may downregulate the CYP3A4 expression, which is the main enzyme for the metabolism of these PAMORA. CYP3A4 inducers or inhibitors could have clinically relevant effects on naloxegol and naldemedine; ${ }^{103}$ therefore, their concomitant use should be avoided. Methylnaltrexone, instead, is not metabolized by the CYP 450, but in patients with creatinine clearance $<30 \mathrm{~mL} /$ $\mathrm{min}$, the dose should be reduced from $12 \mathrm{mg}$ to $8 \mathrm{mg} .{ }^{103}$ Methylnaltrexone is subcutaneously administrated in patients with advanced illness who are receiving palliative care, suffering from OIC and non-responsive to traditional laxative therapies.

In HD patients, several other adverse events have been associated to chronic opioid therapy, although not necessarily related to these drugs. All opioids, indeed, have been reported to increase the risk of falls, fractures, and altered mental status, among HD patients. These effects have been observed also at lower doses and for other drugs commonly recommended in 


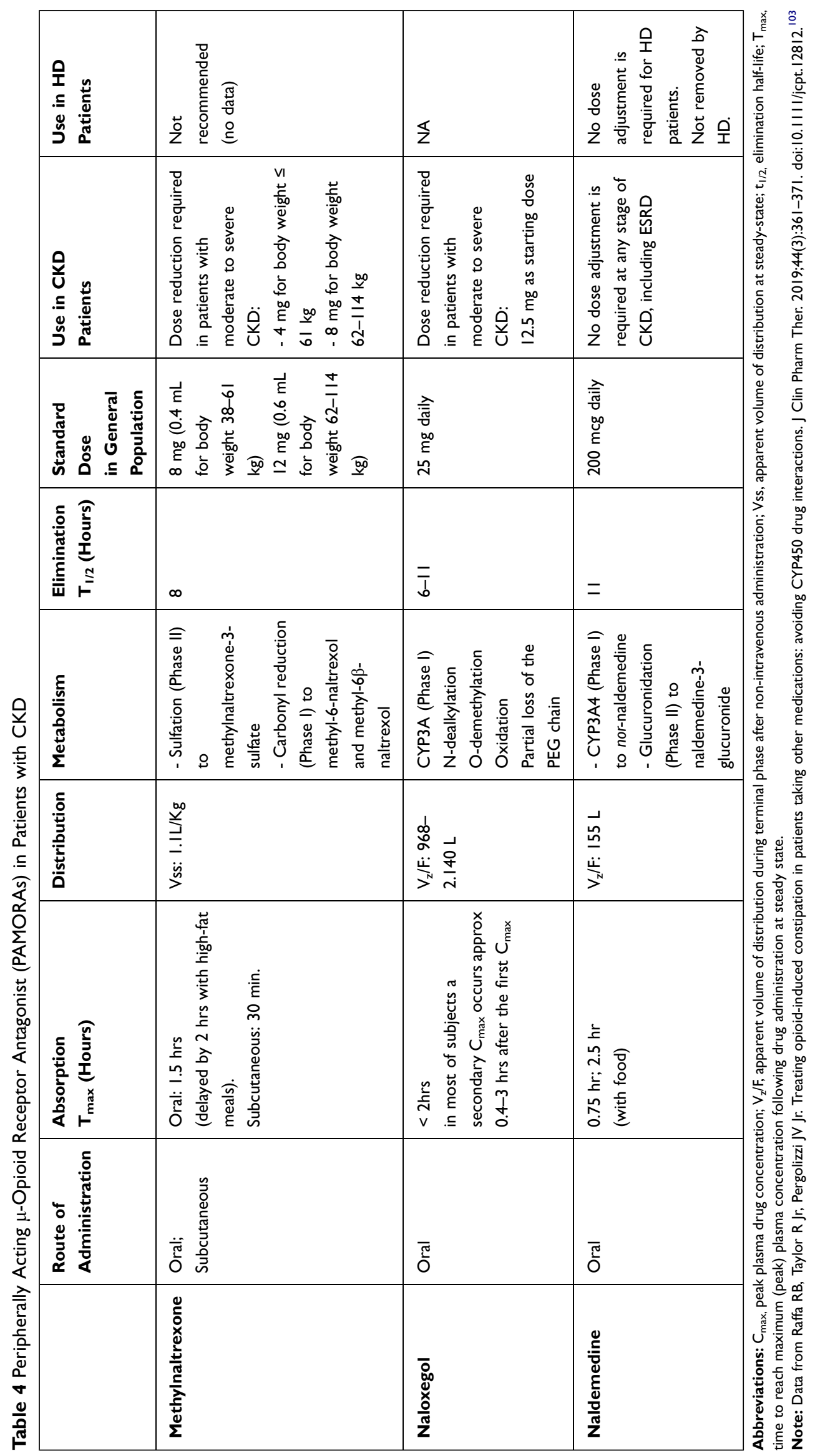


guidelines. ${ }^{104}$ The relationship between opioids and risk of fracture is still object of investigation. Beside the increased risk of falls due to sedative effects of opioids, there are at least other two mechanisms that have been implicated in this process: firstly, opioids directly act on osteoblasts, by affecting the bone turnover; secondly, opioids are well known to inhibit the hypothalamic-pituitary axis (HPA) and to induce androgen deficiency. ${ }^{105}$ One of the possible effects of the HPA suppression is the reduced bone mineral density observed in chronic opioid users and abusers. ${ }^{106}$ The opioid-related endocrinopathy could further worsen the low bone mass density, which is common in ESRD patients, especially those undergoing HD. Moreover, following fracture, opioids have been shown to have a negative effect on bone healing and to increase the risk of nonunion fracture. ${ }^{107}$

Moreover, all opioid drugs have been associated to increased mortality, dialysis discontinuation, and hospitalization. However, as a causal relationship has not been identified, it is reasonable to assume that patients with a worst general physical status more often require opioid use. ${ }^{83}$

Finally, in vulnerable patients, chronic opioid use may be associated with increased risk of dependence and abuse. The inadequate knowledge about the differences between tolerance, physical dependence, and psychological dependence, may be a further barrier to opioid prescription among non-pain specialists involved in the care of CKD patients. Appropriate definitions are useful for differentiating aberrant behaviors, from common conditions that are expected during opioid treatment. Tolerance is a pharmacological process due to a reduced sensitivity or number of opioid receptors, which leads to the need for increasing the dose to reach equal analgesia. Tolerance is also the mechanism by which some adverse events, such as nausea, vomiting, and dizziness, tend to disappear after the first days or weeks of opioid treatment. Physical dependence is the physiological adaption of the body to a drug, and it becomes clinically detectable when the opioid is abruptly withdrawn, without appropriate dose de-escalation. The clinical manifestation is the abstinence syndrome, including pupillary dilation, gastrointestinal disorders, agitation, and tachycardia. As the clinical feature can be shocking for the patient and for his family, they should be carefully advised that opioids must be administered according to the prescription and tapered-down or stopped only in accordance with the physician, through a de-escalation plan. Psychological dependence, or addiction, is uncommon among chronic pain patients, and is characterized by at least one aberrant behavior, such as compulsive use, impaired control over use, use despite harm, and craving.108 Addiction is a disease with biological, neurological, genetic, and environmental sources of origin. Specific data on opioid abuse by CKD and HD patients are not available in literature. However, there are many studies that reported depression and anxiety in approximately one quarter of adults suffering from CKD. ${ }^{109}$ These data on the prevalence of psychological diseases, in this specific setting, suggest attention in patient selection when initiating a treatment with opioids. Different risk tools have been proposed in literature, and could be used for patient selection in challenging situations. ${ }^{110}$ Titration at the beginning of treatment to reach the minimal effective dose, tailoring the drug on the characteristics of the single subject, and eventually tapering the dose, if the opioid is not as effective as expected, are three mandatory rules when managing chronic pain with opioids. ${ }^{111}$ European Pain Federation clearly declared that inadequate and exaggerated fears concerning the legitimate use of opioids for chronic pain management may result in unnecessary patient suffering. ${ }^{86}$

\section{Combination Therapy with Opioids: Patient Safety Issues in CKD}

Patients suffering from CKD and ESRD subjects undergoing HD therapy are usually exposed to a significant number of different drugs. The risks of drug-drug interactions (DDI) in polymedicated patients is well known, particularly in CKD patients. Understanding the vulnerability of this specific population is fundamental for avoiding undesired side effects. ${ }^{112}$

Most opioids, by instance, are metabolized by the CYP450 system, as shown in Table 1. The use of these drugs may lead to the risk of DDI, when co-administrated with CYP inducers or inhibitors.

DDI can be classified as significant, when co-administration of two drugs requires immediate medical intervention or possible life-threatening side effects; in this case, the association is contraindicated. DDI is defined minor or moderate, when they produce limited effects and do not require significant changes in therapy. ${ }^{113}$

Regarding opioids, most of the observed DDI are attributable to the Phase I metabolism via CYP450 isoenzymes, which are also subject to inter-individual genetic variability. DDI may result in a significant increase of the drug concentration, enhancing analgesia, but also increasing the risk of opioid toxicity; or alternatively in the 
reduction of the opioid plasma level; therefore, reducing the analgesic effect. Among drugs commonly used by CKD patients, calcium channel blockers, statins, and other cardiovascular drugs interact with CYP3A4; while beta-blockers, anti-arrhythmic, and glucocorticoids affect CYP2D6 activity. ${ }^{39}$

Moreover, combination therapy with opioids is often required for analgesic purposes. CKD or HD patients suffering from neuropathic or mixed pain are often prescribed with adjuvants (anticonvulsants or antidepressants) and traditional opioids. ${ }^{114}$

Gabapentinoids are the most commonly prescribed drugs for neuropathic pain syndromes. Although their metabolism is not linked to the CYP450 system, association between gabapentin or pregabalin and opioids, such as tramadol, oxycodone, and methadone, may lead to major DDI in patients with renal dysfunction. This is a case of pharmacodynamics interaction, as co-administration of drugs with CNS depressive activity may result dangerous in such a frail population, such as CKD or ESRD patients. Moreover, they are primarily eliminated unchanged in the urine; therefore, their use in ESRD patients require adequate dose adjustments. Conversely, carbamazepine, which is the first-choice drug for trigeminal neuralgia, is a potent enzyme inducer of various CYP450 and p-glycoprotein; therefore, possible DDI could be mostly related to the pharmacokinetic profiles of associated drugs. No dose adjustments are required in ESRD patients, as only $1-3 \%$ of carbamazepine is excreted unchanged in the urine. ${ }^{114}$

Tricyclic antidepressants, such as amitriptyline, and serotonin noradrenaline reuptake inhibitors (SNRIs), such as duloxetine and venlafaxine, are CYP2D6 substrates. These antidepressants are currently a first-choice therapy in neuropathic pain conditions, such as PDPN, which is very common among CKD and HD patients. Duloxetine should be avoided in severe renal failure $(\mathrm{CrCl}<30$ $\mathrm{mL} / \mathrm{min}$ ).

Selective serotonin reuptake inhibitors (SSRIs), such as fluoxetine and paroxetine, are also CYP2D6 substrates. Conversely to TCAs and SNRIs, they are mainly used as antidepressants for treating depression in chronic pain patients, as they are not very effective as analgesic by themselves.

Altered metabolism of antidepressant drugs can result in serotonin syndrome. There are no specific tests for diagnosing serotonin syndrome; clinical diagnosis remains the gold standard and it is based on altered mental status (agitation), heightened neuromuscular activity (spontaneous or inducible clonus, ocular clonus, tremor and hyperreflexia) and altered autonomic activity (diaphoresis and temperature $>38^{\circ} \mathrm{C}$ ). In ESRD patients, the risk of toxicity is increased by a reduced renal clearance of active serotoninergic agents. Tramadol is the most commonly involved opioid in the reported cases of serotonin syndrome, alone or in combination with other serotoninergic medications, because of its dual mechanism of action, including inhibition of 5-HT reuptake. ${ }^{115}$

Conversely, Tapentadol, due to a minimal-to-weak serotonin reuptake inhibitor activity is unlikely to cause serotonin syndrome. Few case reports have been reported in the post-marketing surveillance, when co-administrated with other serotoninergic medications, because of its weak ability to bind $5-\mathrm{HT}_{2 \mathrm{~A}}$ receptors. On the other side, fentanyl, which theoretically is a pure MOR agonist, which is thought to not influence serotonin concentration, has been reported as the second most common opioid involved in serotonin syndromes, when co-administrated with serotoninergic drugs, including antidepressants and antiemetic medications. Fentanyl, indeed, has been recently shown to be a weak inhibitor of the serotonin transporter (SERT); therefore, it produces an efflux of serotonin. Moreover, it binds to $5-\mathrm{HT}_{1 \mathrm{~A}}$ and $5-\mathrm{HT}_{2 \mathrm{~A}}$ receptors. ${ }^{116}$

Finally, monoamine oxidase inhibitors (MAOIs), such as the antibiotics isoniazid or linezolid, used for severe infections, may also induce serotonin syndrome; therefore, their use should be avoided in patients using other serotoninergic medications.

According to these data, the risk of DDI should be always considered when managing chronic pain in CKD patients. In polymedicated patients, particularly, with mixed chronic pain syndromes, where traditional opioids may be ineffective, tapentadol could be considered the most promising opioid, for its dual activity on both neuropathic and nociceptive components of pain, for its nearly CYP450-free metabolism, and for its pharmacological characteristics, which make the drug suitable also for patients with mild to moderate $\mathrm{CKD}$, without dosage adaptation. ${ }^{39}$

\section{Conclusions}

Pain is very common in CKD and HD patients, but most of these subjects are still undertreated. Adequate pain management is mandatory for a better quality of life and for ensuring regular and complete HD sessions. Non-pain specialists may be unfamiliar with different chronic pain syndromes and with safe and appropriate use of opioids. Given the high 
prevalence of chronic pain, as suggested by recommendations for general population, they should consider referral to pain specialists when pain is not adequately managed with standard analgesics. A multidisciplinary team should be involved in the management of vulnerable patients suffering from CKD or undergoing HD.

Implementation of medical education is the best solution for overcoming current barriers to adequate pain management and to avoid physicians' concerns about opioid use. Unfortunately, the number of clinical trials available on the use of opioids in ESRD and HD patients is still limited, and extrapolating information by clinical studies on different populations may not be prudent. Therefore, further trials are warranted to evaluate the efficacy and safety of opioids in CKD and ESRD/HD patients.

\section{Disclosure}

FC served as a speaker and consultant for Grunenthal, Angelini, Malesci, Molteni, Shionogi. DB served as a speaker and consultant for Grunenthal and Alfasigma. SC served as a speaker and consultant for Grunenthal and Angelini. PR served as a speaker and consultant for Grunenthal, Molteni, Camurus, and Angelini. FFC, AP, and MR report no conflict of interest for this work. Funding: This work was supported by Grunenthal for open-access publication.

\section{References}

1. Hildebrandt F. Genetic kidney diseases. Lancet. 2010;375 (9722):1287-1295. doi:10.1016/S0140-6736(10)60236-X

2. Webster AC, Nagler EV, Morton RL, Masson P. Chronic kidney disease. Lancet. 2017;389(10075):1238-1252. doi:10.1016/S01406736(16)32064-5

3. Morton RL, Schlackow I, Mihaylova B, Staplin ND, Gray A, Cass A. The impact of social disadvantage in moderate-to-severe chronic kidney disease: an equity-focused systematic review. Nephrol Dial Transplant. 2016;31(1):46-56. doi:10.1093/ndt/gfu394

4. Cavalli A, Del Vecchio L, Locatelli F. Geriatric nephrology. J Nephrol. 2010;23(Suppl 15):S115.

5. Innis J. Pain assessment and management for a dialysis patient with diabetic peripheral neuropathy. CANNT J. 2006;16(2):12-7, 20-6; quiz $18-9,27-8$.

6. Bakris GL, Williams M, Dworkin L, et al. Preserving renal function in adults with hypertension and diabetes: a consensus approach. National kidney foundation hypertension and diabetes executive committees working group. Am J Kidney Dis. 2000;36(3):646-661. doi:10.1053/ ajkd.2000.16225

7. Davison SN, Koncicki H, Brennan F. Pain in chronic kidney disease: a scoping review. Semin Dial. 2014;27(2):188-204. doi:10.1111/ sdi. 12196

8. Tuegel C, Bansal N. Heart failure in patients with kidney disease. Heart. 2017;103(23):1848-1853. doi:10.1136/heartjnl-2016-310794

9. Reis A, Luecke C, Davis TK, Kakajiwala A. Pain management in pediatric chronic kidney disease. J Pediatr Pharmacol Ther. 2018;23 (3):192-202. doi:10.5863/1551-6776-23.3.192
10. Schaefer F, Wingen AM, Hennicke M, Rigden S, Mehls O. Growth charts for prepubertal children with chronic renal failure due to congenital renal disorders. European study group for nutritional treatment of chronic renal failure in childhood. Pediatr Nephrol. 1996;10(3):288-293. doi:10.1007/BF00866762

11. Harambat J, van Stralen KJ, Kim JJ, Tizard EJ. Epidemiology of chronic kidney disease in children. Pediatr Nephrol. 2012;27 (3):363-373. doi:10.1007/s00467-011-1939-1

12. Xiao N, Jenkins TM, Nehus E, et al. Kidney function in severely obese adolescents undergoing bariatric surgery. Obesity. 2014;22 (11):2319-2325. doi:10.1002/oby.20870

13. Ding W, Cheung WW, Mak RH. Impact of obesity on kidney function and blood pressure in children. World J Nephrol. 2015;4 (2):223-229. doi:10.5527/wjn.v4.i2.223

14. Launay-Vacher V, Oudard S, Janus N, et al. Prevalence of renal insufficiency in cancer patients and implications for anticancer drug management: the renal insufficiency and anticancer medications (IRMA) study. Cancer. 2007;110(6):1376-1384. doi:10.1002/ cncr.22904

15. Almutary H, Bonner A, Douglas C. Which patients with chronic kidney disease have the greatest symptom burden? A comparative study of advanced CKD stage and dialysis modality. J Ren Care. 2016;42(2):73-82. doi:10.1111/jorc. 12152

16. Pham PC, Khaing K, Sievers TM, et al. 2017 update on pain management in patients with chronic kidney disease. Clin Kidney J. 2017;10(5):688-697. doi:10.1093/ckj/sfx080

17. Murtagh FE, Addington-Hall JM, Edmonds PM, et al. Symptoms in advanced renal disease: a cross-sectional survey of symptom prevalence in stage 5 chronic kidney disease managed without dialysis. J Palliat Med. 2007;10(6):1266. doi:10.1089/jpm.2007.0017

18. Murphy EL, Murtagh FE, Carey I, Sheerin NS. Understanding symptoms in patients with advanced chronic kidney disease managed without dialysis: use of a short patient-completed assessment tool. Nephron Clin Pract. 2009;111(1):c7480. doi:10.1159/000183177

19. Noble H, Meyer PJ, Bridge DJ, Johnson DB, Kelly DD. Exploring symptoms in patients managed without dialysis: a qualitative research study. $J$ Ren Care. 2010;36(1):9-15. doi:10.1111/j.1755-6686.2010.00140.x

20. Selewski DT, Massengill SF, Troost JP, et al. Gaining the Patient Reported Outcomes Measurement Information System (PROMIS) perspective in chronic kidney disease: a midwest pediatric nephrology consortium study. Pediatr Nephrol. 2014;29 (12):2347-2356. doi:10.1007/s00467-014-2858-8

21. Douglas CA. Palliative care for patients with advance chronic kidney disease. J R Coll Physicians Edinb. 2014;44(3):224-231. doi:10.4997/JRCPE.2014.309

22. Kramer A, Boenink R, Noordzij M, et al. The ERA-EDTA registry annual report 2017: a summary. Clin Kidney J. 2020. 1-17. doi:10.1093/ckj/sfaa048.

23. United States Renal Data System. 2019 USRDS annual data report: epidemiology of kidney disease in the United States. National institutes of health, national institute of diabetes and digestive and kidney diseases. Bethesda, MD; 2019. Available from: https://usrds.org/2019/view/USRDS_2019_ES_final.pdf. Accessed June 26, 2020.

24. Calls J, Rodríguez Calero M, Hernández Sánchez D, et al. An evaluation of pain in haemodialysis patients using different validated measurement scales. Nefrologia. 2009;29(3):236-243. doi:10.3265/Nefrologia.2009.29.3.5120.en.full

25. Davison SN. Pain in haemodialysis patients: prevalence, cause, severity, and management. Am J Kidney Dis. 2003;42(6):12391247. doi:10.1053/j.ajkd.2003.08.025

26. Brkovic T, Burilovic E, Puljak L. Prevalence and severity of pain in adult end-stage renal disease patients on chronic intermittent haemodialysis: a systematic review. Patient Prefer Adherence. 2016;10:1131-1150. doi:10.2147/PPA.S103927 
27. Murtagh FE, Addington-Hall J, Higginson IJ. The prevalence of symptoms in end-stage renal disease: a systematic review. $A d v$ Chronic Kidney Dis. 2007a;14(1):82-99. doi:10.1053/j.ackd.20 06.10.001

28. Dean M. Opioids in renal failure and dialysis patients. $J$ Pain Symptom Manage. 2004;28(5):497-504. doi:10.1016/j. jpainsymman.2004.02.021

29. Bailie GR, Mason NA, Bragg-Gresham JL, Gillespie BW, Young EW. Analgesic prescription patterns among haemodialysis patients in the DOPPS: potential for underprescription. Kidney Int. 2004;65(6):2419-2425. doi:10.1111/j.1523-1755.20 04.00658.x

30. Coluzzi F. Assessing and treating chronic pain in patients with end-stage renal disease. Drugs. 2018;78(14):1459-1479. doi:10. 1007/s40265-018-0980-9

31. Fallon M, Giusti R, Aielli F, et al. Management of cancer pain in adult patients: ESMO clinical practice guidelines. Ann Oncol. 2018;29(Suppl 4):iv166iv191. doi:10.1093/annonc/mdy152

32. Corder G, Castro DC, Bruchas MR, Scherrer G. Endogenous and exogenous opioids in pain. Annu Rev Neurosci. 2018;8(41):453473. doi:10.1146/annurev-neuro-080317-061522

33. Drewes AM, Jensen RD, Nielsen LM, et al. Differences between opioids: pharmacological, experimental, clinical and economical perspectives. Br J Clin Pharmacol. 2013;75(1):60-78. doi:10. 1111/j.1365-2125.2012.04317.x

34. Pergolizzi JV Jr, Breve F, Jr TR, Raffa RB, Strasburger SE, LeQuang JA. Considering tapentadol as a first-line analgesic: 14 questions. Pain Manag. 2017;Jul(4):331-339. doi:10.2217/pmt2016-0063

35. Raffa RB, Pergolizzi JV, Taylor R, Ossipov MH, NEMA Research Group. Nature's first "atypical opioids": kratom and mitragynines. J Clin Pharm Ther. 2018;43(3):437-441. doi:10. $1111 /$ jcpt. 12676

36. Davis MP, Srivastava M. Demographics, assessment and management of pain in the elderly. Drugs Aging. 2003;20(1):23-57. doi:10.2165/00002512-200320010-00003

37. Levey AS, Becker C, Inker LA. Glomerular filtration rate and albuminuria for detection and staging of acute and chronic kidney disease in adults: a systematic review. JAMA. 2015;313:837-846. doi:10.1001/jama.2015.0602

38. Kidney Disease: Improving Global Outcomes (KDIGO) CKD Work Group. KDIGO 2012 clinical practice guideline for the evaluation and management of chronic kidney disease. Kidney Int. 2013;3(suppl):1-150.

39. Davison SN. Clinical pharmacology considerations in pain management in patients with advanced kidney failure. Clin J Am Soc Nephrol. 2019;14(6):917-931. doi:10.2215/CJN.05180418

40. Wishart DS, Feunang YD, Guo AC, et al. DrugBank 5.0: a major update to the drug Bank database for 2018. Nucleic Acids Res. 2018;46(D1):D1074D1082. doi:10.1093/nar/gkx1037

41. Way EL, Adler TK. The pharmacologic implications of the fate of morphine and its surrogates. Pharmacol Rev. 1960;12:383446.

42. Kurella M, Bennett WM, Chertow GM. Analgesia in patients with ESRD: a review of available evidence. Am J Kidney Dis. 2003;42(2):217-228. doi:10.1016/S0272-6386(03)00645-0

43. Murtagh FE, Chai MO, Donohoe P, Edmonds PM, Higginson IJ. The use of opioid analgesia in end-stage renal disease patients managed without dialysis: recommendations for practice. J. Pain Palliat Care Pharmacother. 2007b;21(2):5-16.

44. Parmar MS, Parmar KS. Management of acute and post-operative pain in chronic kidney disease. Version 3. F1000Res. 2013;2:28. doi:10.12688/f1000research.2-28.v2

45. Guay DR, Awni WM, Findlay JW, et al. Pharmacokinetics and pharmacodynamics of codeine in end-stage renal disease. Clin Pharmacol Ther. 1988;43(1):63-71. doi:10.1038/clpt.1988.12
46. Kirchheiner J, Schmidt H, Tzvetkov M, et al. Pharmacokinetics of codeine and its metabolite morphine in ultra-rapid metabolizers due to CYP2D6 duplication. Pharmacogenomics J. 2007;7 (4):257-265. doi:10.1038/sj.tpj.6500406

47. Launay-Vacher V, Karie S, Fau JB, Izzedine H. Deray G treatment of pain in patients with renal insufficiency: the World Health Organization three-step ladder adapted. J Pain. 2005;6(3):137. doi:10.1016/j.jpain.2004.11.009

48. Murphy EJ. Acute pain management pharmacology for the patient with concurrent renal or hepatic disease. Anaesth Intensive Care. 2005;33(3):311-322. doi:10.1177/0310057X0503300306

49. King S, Forbes K, Hanks GW, Ferro CJ, Chambers EJ. A systematic review of the use of opioid medication for those with moderate to severe cancer pain and renal impairment: a European palliative care research collaborative opioid guidelines project. Palliat Med. 2011;25(5):525-552. doi:10.1177/0269216311406313

50. Kalso E. Oxycodone. J Pain Symptom Manage. 2005;29(5 Suppl):S4756. doi:10.1016/j.jpainsymman.2005.01.010

51. Samolsky Dekel BG, Donati G, Vasarri A, et al. Dialyzability of oxycodone and its metabolites in chronic noncancer pain patients with end-stage renal disease. Pain Pract. 2017;17(5):604-615. doi:10.1111/papr.12483

52. Kirvela M, Lindgren L, Seppala T, Olkkola KT. The pharmacokinetics of oxycodone in uremic patients undergoing renal transplantation. J Clin Anesth. 1996;8(1):13-18. doi:10.1016/0952$8180(95) 00092-5$

53. Fitzgerald J. Narcotic analgesics in renal failure. Conn Med. 1991;55(12):701-704.

54. Lee CR, McTavish D, Sorkin EM. Tramadol. A preliminary review of its pharmacodynamic and pharmacokinetic properties, and therapeutic potential in acute and chronic pain states. Drugs. 1993;46(2):313-340. doi:10.2165/00003495-199346020-00008

55. Gibson TP. Pharmacokinetics, efficacy, and safety of analgesia with a focus on tramadol HCl. Am J Med. 1996;101(1A):47S53S. doi:10.1016/S0002-9343(96)00138-6

56. Izzedine H, Launay-Vacher V, Abbara C, Aymard G, Bassilios N, Deray G. Pharmacokinetics of tramadol in a haemodialysis patient. Nephron. 2002;92(3):755-756. doi:10.1159/000064092

57. Fainsinger R, Schoeller T, Boiskin M, Bruera E. Palliative care round: cognitive failure and coma after renal failure in a patient receiving captopril and hydromorphone. J Palliat Care. 1993;9 (1):53-55. doi:10.1177/082585979300900110

58. Babul N, Darke AC, Hagen N. Hydromorphone metabolite accumulation in renal failure. J Pain Symptom Manage. 1995;10 (3):184-186. doi:10.1016/0885-3924(94)00121-Z

59. Davison SN, Mayo PR. Pain management in chronic kidney disease: the pharmacokinetics and pharmacodynamics of hydromorphone and hydromorphone-3-glucuronide in haemodialysis patients. J Opioid Manag. 2008;4(6):335-6, 339-44.

60. Lee MA, Leng ME, Tiernan EJ. Retrospective study of the use of hydromorphone in palliative care patients with normal and abnormal urea and creatinine. Palliat Med. 2001;15(1):26-34. doi:10.1191/026921601669626431

61. Paramanandam G, Prommer E, Schwenke DC. Adverse effects in hospice patients with chronic kidney disease receiving hydromorphone. J Palliat Med. 2011;14(9):1029-1033. doi:10.1089/jpm. 2011.0103

62. Kreek MJ, Schecter AJ, Gutjahr CL, Hecht M. Methadone use in patients with chronic renal disease. Drug Alcohol Depend. 1980;5 (3):197-205. doi:10.1016/0376-8716(80)90180-5

63. Furlan V, Hafi A, Dessalles MC, Bouchez J, Charpentier B, Taburet AM. Methadone is poorly removed by haemodialysis. Nephrol Dial Transplant. 1999;14(1):254-255. doi:10.1093/ndt/ 14.1.254

64. Mercadante S, Arcuri E. Opioids and renal function. $J$ Pain. 2004;5:2-19. doi:10.1016/j.jpain.2003.09.007 
65. Koehntop DE, Rodman JH. Fentanyl pharmacokinetics in patients undergoing renal transplantation. Pharmacotherapy. 1997;17 (4):746-752.

66. Bower S. Plasma protein binding of fentanyl: the effect of hyperlipoproteinaemia and chronic renal failure. J Pharm Pharmacol. 1982;34(2):102-106. doi:10.1111/j.2042-7158.1982.tb04194.x

67. Davies G, Kingswood C, Street M. Pharmacokinetics of opioids in renal dysfunction. Clin Pharmacokinet. 1996;31(6):410-422. doi:10.2165/00003088-199631060-00002

68. Mercadante S, Caligara M, Sapio M, Serretta R, Lodi F. Subcutaneous fentanyl infusion in a patient with bowel obstruction and renal failure. J Pain Symptom Manage. 1997;13(4):241244. doi:10.1016/S0885-3924(97)00076-6

69. Bastani B, Jamal JA. Removal of morphine but not fentanyl during haemodialysis. Nephrol Dial Transplant. 1997;12 (12):2802-2804. doi:10.1093/ndt/12.12.2802

70. Joh J, Sila MK, Bastani B. Nondialyzability of fentanyl with high-efficiency and high-flux membranes. Anesth Analg. 1998;86(2):447.

71. Han J, Saraf SL, Gordeuk VR. Gowhari M3. Safety of chronic transdermal fentanyl use in patients receiving haemodialysis. Am J Health Syst Pharm. 2016;73(13):947-948. doi:10.2146/ajhp150748

72. Hand CW, Sear JW, Uppington J, Ball MJ, McQuay HJ, Moore RA. Buprenorphine disposition in patients with renal impairment: single and continuous dosing, with special reference to metabolites. $\mathrm{Br} J$ Anaesth. 1990;64(3):276-282. doi:10.1093/bja/64.3.276

73. Filitz J, Griessinger N, Sittl R, Likar R, Schüttler J, Koppert W. Effects of intermittent haemodialysis on buprenorphine and norbuprenorphine plasma concentrations in chronic pain patients treated with transdermal buprenorphine. Eur J Pain. 2006;10 (8):743-748. doi:10.1016/j.ejpain.2005.12.001

74. Cone EJ, Gorodetzky CW, Yousefnejad D, Buchwald WF, Johnson RE. The metabolism and excretion of buprenorphine in humans. Drug Metab Dispos. 1984;12(5):577-581.

75. Böger RH. Renal impairment: a challenge for opioid treatment? The role of buprenorphine. Palliat Med. 2006;20(Suppl 1):s1723.

76. Kress HG. Clinical update on the pharmacology, efficacy and safety of transdermal buprenorphine. Eur J Pain. 2009;13 (3):219-230. doi:10.1016/j.ejpain.2008.04.011

77. Tzschentke TM, Jahnel U, Kogel B, et al. Tapentadol hydrochloride: a next generation, centrally acting analgesic with two mechanisms of action in a single molecule. Drugs of Today. 2009;45(7):483-496.

78. Terlinden R, Kogel BY, Englberger W, Tzschentke TM. In vitro and in vivo characterization of tapentadol metabolites. Methods Find Exp Clin Pharmacol. 2010;32(1):31-38. doi:10.1358/ mf.2010.32.1.1434165

79. Vadivelu N, Huang Y, Mirante B, et al. Patient considerations in the use of tapentadol for moderate to severe pain. Drug Healthc Patient Saf. 2013;5:151-159. doi:10.2147/DHPS.S28829

80. Hale M, Upmalis D, Okamoto A, Lange C, Rauschkolb C. Tolerability of tapentadol immediate release in patients with lower back pain or osteoarthritis of the hip or knee over 90 days: A randomized, double blind study. Curr Med Res Opin. 2009;25:1095-1104. doi:10.1185/03007990902816970

81. Butler AM, Kshirsagar AV, Brookhart MA. Opioid use in the US haemodialysis population. Am J Kidney Dis. 2014;63(1):171-173. doi:10.1053/j.ajkd.2013.09.008

82. Wyne A, Rai R, Cuerden M, Clark WF, Suri RS. Opioid and benzodiazepine use in end-stage renal disease: a systematic review. Clin J Am Soc Nephrol. 2011;6(2):326-333. doi:10.22 15/CJN.04770610

83. Kimmel PL, Fwu CW, Abbott KC, Eggers AW, Kline PP, Eggers PW. Opioid prescription, morbidity, and mortality in united states dialysis patients. J Am Soc Nephrol. 2017;28(12):3658-3670. doi:10.1681/ASN.2017010098
84. Kern DM, Zhou S, Chavoshi S, et al. Treatment patterns, healthcare utilization, and costs of chronic opioid treatment for noncancer pain in the United States. Am J Manag Care. 2015;21(3): e22234.

85. Eerdekens M, Beuter C, Lefeber C, van den Anker J. The challenge of developing pain medications for children: therapeutic needs and future perspectives. J Pain Res. 2019;23(12):16491664. doi:10.2147/JPR.S195788

86. Coluzzi F. "I am in pain": is it really the magic formula to open the door of opioid abuse? Minerva Anestesiol. 2017;83(12):13321333. doi:10.23736/S0375-9393.17.12269-8

87. O'Brien T, Christrup LL, Drewes AM, et al. European Pain Federation position paper on appropriate opioid use in chronic pain management. Eur J Pain. 2017;21(1):3-19. doi:10.1002/ejp.970

88. Coluzzi F, Fornasari D, Pergolizzi J, Romualdi P. From acute to chronic pain: tapentadol in the progressive stages of this disease entity. Eur Rev Med Pharmacol Sci. 2017;21(7):1672-1683.

89. Vadivelu N, Kai A, Maslin B, Kodumudi G, Legler A, Berger JM. Tapentadol extended release in the management of peripheral diabetic neuropathic pain. Ther Clin Risk Manag. 2015;14 (11):95-105. doi:10.2147/TCRM.S32193

90. Coluzzi F, Polati E, Freo U, Grilli M. Tapentadol: an effective option for the treatment of back pain. J Pain Res. 2019;16 (12):1521-1528. doi:10.2147/JPR.S190176

91. Kress HG, Coluzzi F. Tapentadol in the management of cancer pain: current evidence and future perspectives. J Pain Res. 2019;16(12):1553-1560. doi:10.2147/JPR.S191543

92. Yamamoto S, Kazama JJ, Maruyama H, Nishi S, Narita I, Gejyo F. Patients undergoing dialysis therapy for 30 years or more survive with serious osteoarticular disorders. Clin Nephrol. 2008;70(6):496-502. doi:10.5414/CNP70496

93. Kessler M, Netter P, Azoulay E, Mayeux D, Pere P, Gaucher A. Dialysis-associated arthropathy: a multicentre survey of 171 patients receiving haemodialysis for over 10 years. The co-operative group on dialysis-associated arthropathy. $\mathrm{Br} J$ Rheumatol. 1992;31(3):157-162. doi:10.1093/rheumatology/31.3.157

94. Lee DI, Andreoni CR, Rehman J, et al. Laparoscopic cyst decortication in autosomal dominant polycystic kidney disease: impact on pain, hypertension, and renal function. $J$ Endourol. 2003;17(6):345-354. doi:10.1089/089277903767923100

95. Kumar S, Trivedi HL, Smith EK. Carpal tunnel syndrome: a complication of arteriovenous fistula in haemodialysis patients. Can Med Assoc J. 1975;113(1112):1070-1072.

96. Liu JT, Su CH, Chen SY, Liew SJ, Chang CS. Spinal cord stimulation improves the microvascular perfusion insufficiency caused by critical limb ischemia. Neuromodulation. 2018;21 (5):489-494. doi:10.1111/ner.12753

97. Aitken E, McLellan A, Glen J, Serpell M, Mactier R, Clancy M. Pain resulting from arteriovenous fistulae: prevalence and impact. Clin Nephrol. 2013;80(5):328-333. doi:10.5414/CN107917

98. Göksan B, Karaali-Savrun F, Ertan S, Savrun M. Haemodialysisrelated headache. Cephalalgia. 2004;24(4):284-287. doi:10.1111/ j.1468-2982.2004.00668.x

99. Ambrosio F, Finco G, Mattia C, et al. SIAARTI recommendations for chronic noncancer pain. Minerva Anestesiol. 2006;72(11): 859-880.

100. Coluzzi F, Scerpa MS, Pergolizzi J. Naldemedine: a new option for OIBD. J Pain Res. 2020;13:1209-1222. doi:10.2147/JPR.S243435

101. Bui K, She F, Sostek M. The effects of renal impairment on the pharmacokinetics, safety, and tolerability of naloxegol. J Clin Pharmacol. 2014;54(12):1375-1382. doi:10.1002/jcph.349

102. Webster LR, Hale ME, Yamada T, Wild JE. A renal impairment subgroup analysis of the safety and efficacy of naldemedine for the treatment of opioid-induced constipation in patients with chronic non-cancer pain receiving opioid therapy. J Pain Res. 2020;13:605-612. doi:10.2147/JPR.S237833 
103. Raffa RB, Taylor R Jr, Pergolizzi JV Jr. Treating opioid-induced constipation in patients taking other medications: avoiding CYP450 drug interactions. J Clin Pharm Ther. 2019;44(3):361371. doi:10.1111/jcpt. 12812

104. Ishida JH, McCulloch CE, Steinman MA, Grimes BA, Johansen KL. Opioid analgesics and adverse outcomes among hemodialysis patients. Clin J Am Soc Nephrol. 2018;13(5):746-753. doi:10.2215/CJN.09910917

105. Coluzzi F, Pergolizzi J, Raffa RB, Mattia C. The unsolved case of "bone-impairing analgesics": the endocrine effects of opioids on bone metabolism. Ther Clin Risk Manag. 2015;31(11):515-523. doi:10.2147/TCRM.S79409

106. Coluzzi F, Billeci D, Maggi M, Corona G. Testosterone deficiency in non-cancer opioid-treated patients. $J$ Endocrinol Invest. 2018;41(12):1377-1388. doi:10.1007/s40618-018-0964-3

107. Coluzzi F, Scerpa MS, Centanni M. The effect of opiates on bone formation and bone healing. Curr Osteoporos Rep. 2020;18:325335. doi:10.1007/s11914-020-00585-4

108. Coluzzi F, Bifulco F, Cuomo A, et al. The challenge of perioperative pain management in opioid-tolerant patients. Ther Clin Risk Manag. 2017;5(13):1163-1173. doi:10.2147/TCRM.S141 332

109. Palmer S, Vecchio M, Craig JC, et al. Prevalence of depression in chronic kidney disease: systematic review and meta-analysis of observational studies. Kidney Int. 2013;84(1):179-191. doi:10. 1038/ki.2013.77
110. Pergolizzi JV, Lequang JA, Passik S, Coluzzi F. Using opioid therapy for pain in clinically challenging situations: questions for clinicians. Minerva Anestesiol. 2019;85(8):899-908. doi:10.23736/S0375-9393. 19.13321-4

111. Coluzzi F, Taylor R Jr, Pergolizzi JV Jr, Mattia C, Raffa RB. Good clinical practice guide for opioids in pain management: the three Ts titration (trial), tweaking (tailoring), transition (tapering). Braz J Anesthesiol. 2016;66(3):310-317. doi:10.1016/j.bjan.2016.02.008

112. Triantafylidis LK, Hawley CE, Perry LP, Paik JM. The role of deprescribing in older adults with chronic kidney disease. Drugs Aging. 2018;35(11):973-984. doi:10.1007/s40266-018-0593-8

113. Marquito AB, Fernandes NM, Colugnati FA, de Paula RB. Identifying potential drug interactions in chronic kidney disease patients. J Bras Nefrol. 2014;36(1):26-34. doi:10.5935/01012800.20140006

114. Raouf M, Bettinger J, Wegrzyn EW, Mathew RO, Fudin JJ. Pharmacotherapeutic management of neuropathic pain in endstage renal disease. Kidney Dis. 2020;6(3):157-167. doi:10.11 59/000504299

115. Takeshita J, Litzinger MH. Serotonin syndrome associated with tramadol. Prim Care Companion J Clin Psychiatry. 2009;11:273. doi:10.4088/PCC.08100690

116. Baldo BA, Rose MA. The anaesthetist, opioid analgesic drugs, and serotonin toxicity: a mechanistic and clinical review. $\mathrm{Br} J$ Anaesth. 2020;124(1):44-62. doi:10.1016/j.bja.2019.08.010
Therapeutics and Clinical Risk Management

\section{Publish your work in this journal}

Therapeutics and Clinical Risk Management is an international, peerreviewed journal of clinical therapeutics and risk management, focusing on concise rapid reporting of clinical studies in all therapeutic areas, outcomes, safety, and programs for the effective, safe, and sustained use of medicines. This journal is indexed on PubMed Central, CAS,

\section{Dovepress}

EMBase, Scopus and the Elsevier Bibliographic databases. The manuscript management system is completely online and includes a very quick and fair peer-review system, which is all easy to use. Visit http://www.dovepress.com/testimonials.php to read real quotes from published authors. 